\title{
Preparation and Characterization of the Structural, Optical, Spectroscopic and Electrical Properties of $\operatorname{Pr}_{2} \mathrm{O}_{5}$ doped Borate Glass
}

\author{
Deepa Ananthanarayanan Vasumathy ${ }^{a}$, Priya Murugasen ${ }^{b}$, Suresh Sagadevan ${ }^{c}$ \\ ${ }^{a} R \& D$ Centre, Bharathiar University, Coimbatore, India. \\ ${ }^{b}$ Department of Physics, Saveetha Engineering College, Thandalam, Chennai, 602105, India \\ ${ }^{c}$ Department of Physics, AMET University, Chennai, 603 112, India
}

Received: January 9, 2016; Revised: May 7, 2016; Accepted: June 25, 2016

\begin{abstract}
We have successfully synthesized $\operatorname{Pr}_{2} \mathrm{O}_{5}$ doped borate glasses by conventional rapid melt quench method. The XRD pattern indicates the amorphous nature of $\mathrm{Pr}_{2} \mathrm{O}_{5}$ doped borate glass. An optical property of prepared borate glass was studied using the Photoluminescence spectrum. Determination and differentiation of the various vibrational modes were done using FTIR spectroscopy studies. Raman spectroscopy of $\operatorname{Pr}_{2} \mathrm{O}_{5}$ doped borate glass was also carried out. Thermal analyses of the glasses were done using the TGA/ DTA and DSC analysis. The dielectric properties such as dielectric constant, the dielectric loss and AC conductivity of the $\mathrm{Pr}_{2} \mathrm{O}_{5}$ doped borate glass were studied in the different frequencies and temperature.
\end{abstract}

Keywords: $\mathrm{Pr}_{2} \mathrm{O}_{5}$, XRD, Photoluminescence, FTIR, FT-Raman studies and Dielectric studies

\section{Introduction}

Rare earth ions have numerous attractive spectroscopic properties in glasses in connection with laser research ${ }^{1,2}$, related applications ${ }^{3}$ and basic research ${ }^{4}$. The trivalent rare earth ions are easily incorporated in glasses. $\mathrm{Pr}^{3+}$ doped glasses have transition in the visible region. Some spectral studies have been reported for $\mathrm{Pr}^{3+}$ doped borate and phosphate glasses earlier ${ }^{5-16}$. Recent studies reported ${ }^{17}$ on the applications of $\mathrm{Pr}^{3+}$ doped borophosphate glasses. In many optical devices like blue up-converters $\left({ }^{3} \mathrm{P}_{0}-\right.$ $\left.{ }^{3} \mathrm{H}_{4}\right)$, solid-state lasers emitting visible $\left({ }^{1} \mathrm{D}_{2}-{ }^{3} \mathrm{H}_{4}\right)$ or near-infrared light $\left({ }^{1} \mathrm{G}_{4}-{ }^{3} \mathrm{H}_{5}\right)$ praseodymium - doped glasses are proved to be effective. In the present work, we report the structural properties of the $\mathrm{Pr}_{2} \mathrm{O}_{5}$ doped borate glasses that were determined by X-ray diffraction (XRD) analysis and FTIR and FT-Raman analysis. It was confirmed that the prepared glasses were amorphous. The bonding parameters of the glasses were analyzed by using FTIR and FT Raman analysis and were confirmed to be ionic in nature. The optical properties were characterized by using the photoluminescence studies. The electrical properties of $\operatorname{Pr}_{2} \mathrm{O}_{5}$ doped borate glasses were studied. Since being a member of Lanthanide, Prasuedomium shows efficient luminescence in triplet state. Hence, the prepared borate glass can be used for some applications like optical data reading, colour display etc.

\section{Experimental Procedure}

\subsection{Preparation of Glass Samples}

The $\operatorname{Pr}_{2} \mathrm{O}_{5}$ doped borate glass of composition $\left[60.5 \mathrm{~B}_{2} \mathrm{O}_{3}+\mathrm{xLi}_{2} \mathrm{CO}_{3}+\mathrm{xZno}+\mathrm{xSr}_{2} \mathrm{O}_{3}+\mathrm{xH}_{6} \mathrm{NO}_{4} \mathrm{P}+\mathrm{x}_{1} \mathrm{Y}_{2} \mathrm{O}_{3}\right.$ $+\mathrm{x}{ }_{1} \operatorname{Pr}_{2} \mathrm{O}_{5}$ ( $\mathrm{x}$ in molecular $\%$ ranging from 10 to 50 and $\mathrm{x}_{1}$ in molecular $\%$ of 0.5 ] was prepared by melt quenching method. The appropriate quantities of $\mathrm{B}_{2} \mathrm{O}_{3}$, $\mathrm{Li}_{2} \mathrm{CO}_{3}, \mathrm{ZnO}, \mathrm{Sr}_{2} \mathrm{O}_{3}, \mathrm{Y}_{2} \mathrm{O}_{3}$ and $\mathrm{Pr} 2 \mathrm{O} 5$ were weighed and mixed together with a morter, to get fine powders. All powders were taken in $99.99 \%$ of purity. The batches were placed in a porcelin crucible and melted in electric furnace at $1300^{\circ} \mathrm{C}$. After finishing the melting process, it transferred to a second furnace which maintained at $400{ }^{\circ} \mathrm{C}$ for annealing. The annealing process continued for 3-4 hrs and the sample was gradually cooled under room temperature. The prepared glasses were polished for performing different characterization.

\section{Results and Discussion}

\subsection{XRD characterization}

The X-ray diffraction pattern of the prepared borate glasses were recorded in the range of $20^{\circ}-80^{\circ}$. The results showed that the XRD pattern of the sample exhibited broad diffusion at lower scattering angles. It indicates the presence of long range structural disorder, which is characteristic of amorphous nature as shown in Figure 1. A broad diffuse scattering at different angles instead of crystalline peaks are exhibited confirming a long range structural disorder which is the characteristic of amorphous network.

\subsection{Optical Properties}

The photoluminescence studies given many information like the spontaneous emission of light from a material under excitation and the features of emission spectrum used to identify impurity level,emission 


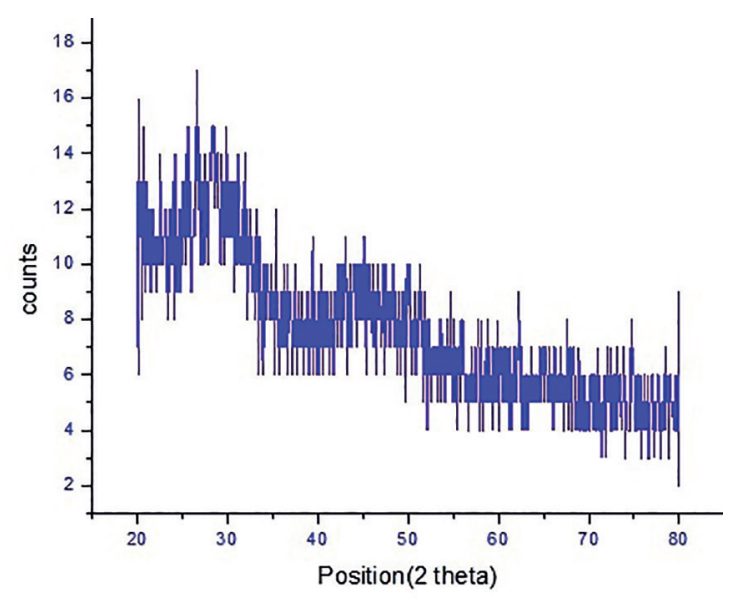

Figure 1: X-ray diffraction pattern of the $\operatorname{Pr}_{2} \mathrm{O}_{5}(\mathrm{x}=10 \%$ and $\mathrm{x} 1=$ $0.5 \%$ ) doped borate glasses.

wavelength etc. Figure 2 shows the excited spectrum of praseodymium doped borate glass. Weak features were displayed between 200 and $320 \mathrm{~nm}$ and single, strong band centered at $361 \mathrm{~nm}$ which indicates the lowest $4 \mathrm{f}-5 \mathrm{~d}$ transition of $\mathrm{Pr}^{3+}$. In accordance with previous studies of $\mathrm{Pr}^{3+}$, it happened due to the charge transfer of $\mathrm{Pr}^{3+}-\mathrm{O}_{2}^{-}$transition at shorter wavelengths ${ }^{18}$.

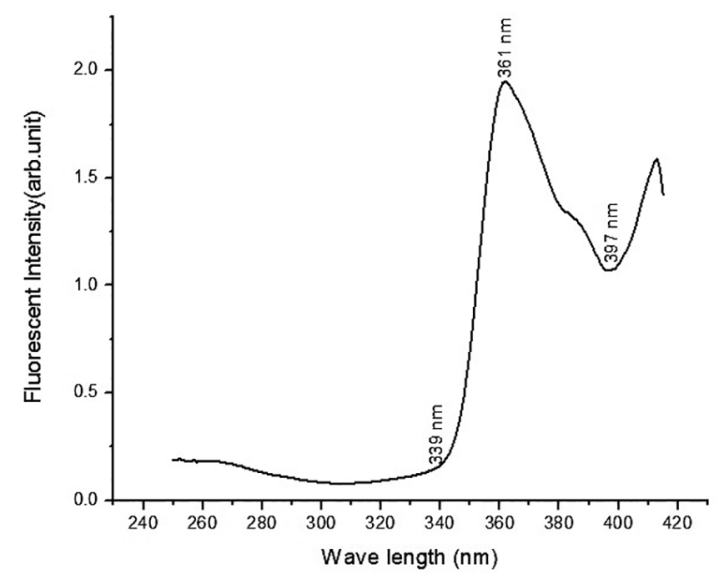

Figure 2: The excited spectrum of $\operatorname{Pr}_{2} \mathrm{O}_{5}(\mathrm{x}=10 \%$ and $\mathrm{x} 1=0.5$ $\%$ ) doped borate glass

The excited $\mathrm{Pr}^{3+}$ ions decay from ${ }^{3} \mathrm{P}$ to ground state by emitting radiations in visible or UV spectrum. Emission peaks were observed at $375 \mathrm{~nm}, 413 \mathrm{~nm}, 436$ $\mathrm{nm}$ and $496 \mathrm{~nm}$ for an excitation of $260 \mathrm{~nm}$ shown in figure 3 . The observed reading agrees well with previous studies ${ }^{19}$. These lines correspond to transitions like ${ }^{3} \mathrm{P}_{2}$ $-{ }^{3} \mathrm{H}_{4},{ }^{3} \mathrm{P}_{0}{ }^{3} \mathrm{H}_{4}$. It is found that, at a peak of wavelength $496 \mathrm{~nm}$, the fluorescence intensity gradually decreases .The transition ${ }^{3} \mathrm{P}_{0}-{ }_{-}^{3} \mathrm{H}_{4}$ can execute Laser action with blue colour. Hence the prepared glass can be used as a blue up converter in Fibre Optic communication field.

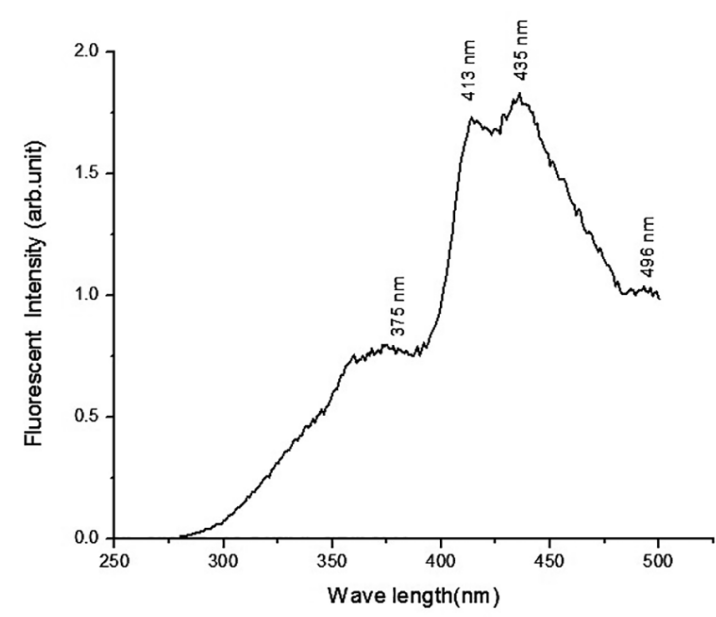

Figure 3: Emission spectrum of $\operatorname{Pr}_{2} \mathrm{O}_{5}(\mathrm{x}=10 \%$ and $\mathrm{x} 1=0.5 \%)$ doped borate glass.

\subsection{Spectral Analysis}

\subsubsection{FTIR analysis}

Infra-red spectrum of borate glass doped with $\mathrm{Pr}_{2} \mathrm{O}_{5}$ in the range of $500-4500 \mathrm{~cm}^{-1}$ is shown in Figure 4. In this region bands are connected with vibrations of borate network. Borate ring deformation $\left(662 \mathrm{~cm}^{-}\right.$ $\left.{ }^{1}\right), \mathrm{BO}_{3}$ bending $\left(791 \mathrm{~cm}^{-1}\right)$, stretching vibration of tetrahedral $\mathrm{BO}_{4}$ group $\left(950-1200 \mathrm{~cm}^{-1}\right)$ are included along with two absorption bands due to stretching of trigonal and tetrahedral $\mathrm{BO}_{4}\left(1200-1400 \mathrm{~cm}^{-1}\right)$ and the bending modes of $\mathrm{OH}$ groups $\left(1700 \mathrm{~cm}^{-1}\right)$. In this spectrum, bending vibration occurs at lower frequencies than stretching vibration. The other absorption bands which are observed indicate weak transitions. The second broad band shows four lines appearing at 955 , 1180,1376 and $1159 \mathrm{~cm}^{-1}$, due to the P-O symmetric $\left(v_{\mathrm{s}}\right)$ and asymmetric $\left(v_{\mathrm{as}}\right)$ stretching vibrations. The intensity of these lines increases with $\operatorname{Pr}_{2} \mathrm{O}_{5}$ content.

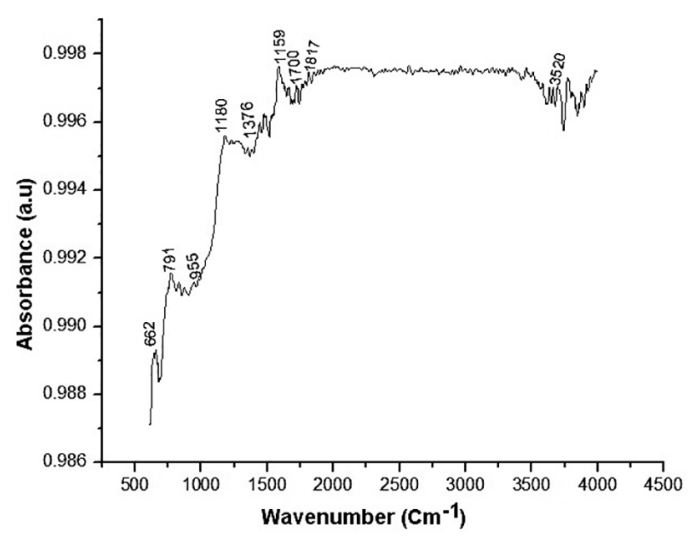

Figure 4: IR spectrum of $\operatorname{Pr}_{2} \mathrm{O}_{5}(\mathrm{x}=10 \%$ and $\mathrm{x} 1=0.5 \%)$ doped borate glass 


\subsubsection{FT-Raman analysis}

Raman spectrum of the prepared glass with broad peak is observed in the range of 500- 2000 $\mathrm{cm}^{-1}$ as shown in Figure 5.The position of peaks in the spectrum defined the molecular structure of the sample. The symmetric stretching peak at $687 \mathrm{~cm}^{-1}$ looks more intense compared to others. Generally asymmetric stretching vibrations cause less intensity peaks only. The disorder in the glass matrix results in the broadening of the peaks.

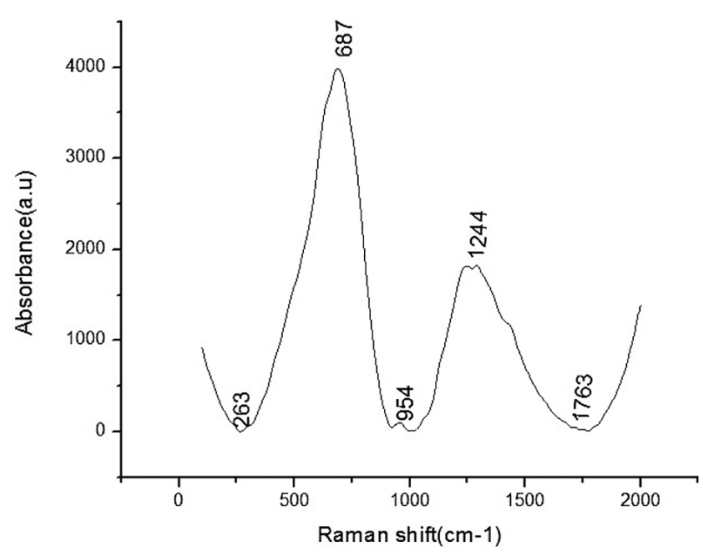

Figure 5: Raman spectrum of $\operatorname{Pr}_{2} \mathrm{O}_{5}(\mathrm{x}=10 \%$ and $\mathrm{x} 1=0.5 \%)$ doped borate glass

\subsubsection{Thermal analysis}

Thermogravimetric analysis is a technique to assess the stability of various substances. Figure 6 shows the simultaneously recorded thermogravimetric analysis (TGA) and differential thermogravimetric analysis (DTA) curve for $\operatorname{Pr}_{2} \mathrm{O}_{5}$ doped borate glass. The amorphous nature of the glasses was confirmed using the TGA and DTA curves. .The endothermic peaks corresponding to the glass transition $\left(\mathrm{T}_{\mathrm{g}}\right)$ and exothermic peaks due to the crystallization (Tp) are observed. It allows concluding that melt - quenched samples are glasses. No appreciable weight loss was detected in the TGA measurements in the glass sample. The weight loss of the first step corresponds to water released in the sample and other steps correspond to the decomposition of the samples which is shown in Figure 6. The lack of sharp endothermic and exothermic peaks evidently specifies the formation of homogeneous glass. Figure 7 shows the differential thermal analysis of the glasses under investigation. The glass exhibits change due to the glass transition temperature $\mathrm{T}_{\mathrm{g}}$ at $218^{\circ} \mathrm{C}$. It is also observed that, during higher temperature an exothermic peak Tc formed at $677^{\circ} \mathrm{C}$ due to the crystal growth, which is followed by a single sharp endothermic effect, due to the melting of the glass, as symbolized by Tm at $1200^{\circ} \mathrm{C}$.

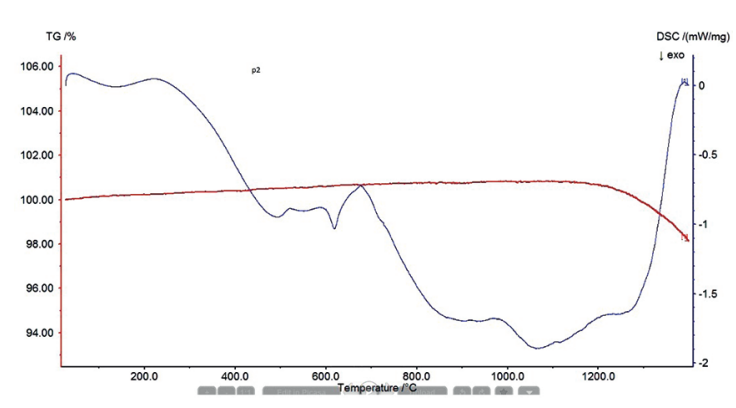

Figure 6: $\mathrm{TGA}_{\text {of }} \mathrm{Pr}^{3+}(\mathrm{x}=10 \%$ and $\mathrm{x} 1=0.5 \%)$ doped borate glass.

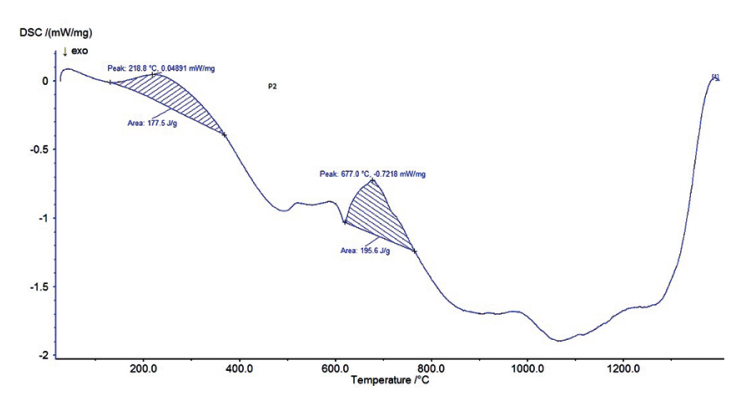

Figure 7: $\mathrm{DSC}$ of $\operatorname{Pr}^{3+}(\mathrm{x}=10 \%$ and $\mathrm{x} 1=0.5 \%)$ doped borate glass.

\subsection{Dielectric Studies}

The dielectric properties of the $\operatorname{Pr}_{2} \mathrm{O}_{5}$ doped borate glass was measured using HIOKI 3532 - 50 LCR meter in the frequency ranging from $50 \mathrm{~Hz}$ to $5 \mathrm{MHz}$. The frequency dependence of dielectric constant at different temperatures is shown in Figure 8 (a). The dielectric constant decreases very rapidly at low frequencies and then slowly, as the frequency increases and finally, it becomes almost a constant at higher frequencies. The high value of dielectric constant at low frequencies may be associated with the establishment of polarizations namely; space charge, orientational, electronic and ionic polarization. Its low value at higher frequencies is attributed due to the loss of significance of these polarizations gradually. At high frequencies, normally orientation and space charge polarization exists. This behavior can be attributed to the applied electric field, which assists electron hopping between two different sites in glasses. The jump frequency of the charge carrier becomes large and comparable with the frequency of the applied field at high temperatures. At low frequency the charge carriers hop easily out of the sites with low free energy and tend to accumulate at sites with high free energy barriers. Hence a net polarization is developed and gives an increase in the dielectric constant and dielectric loss. However at high frequency, the charge carriers will not be able to rotate sufficiently, so their oscillation will begin to lay behind field resulting in a decrease of dielectric constant and dielectric loss. Jump frequency of the charge carries 


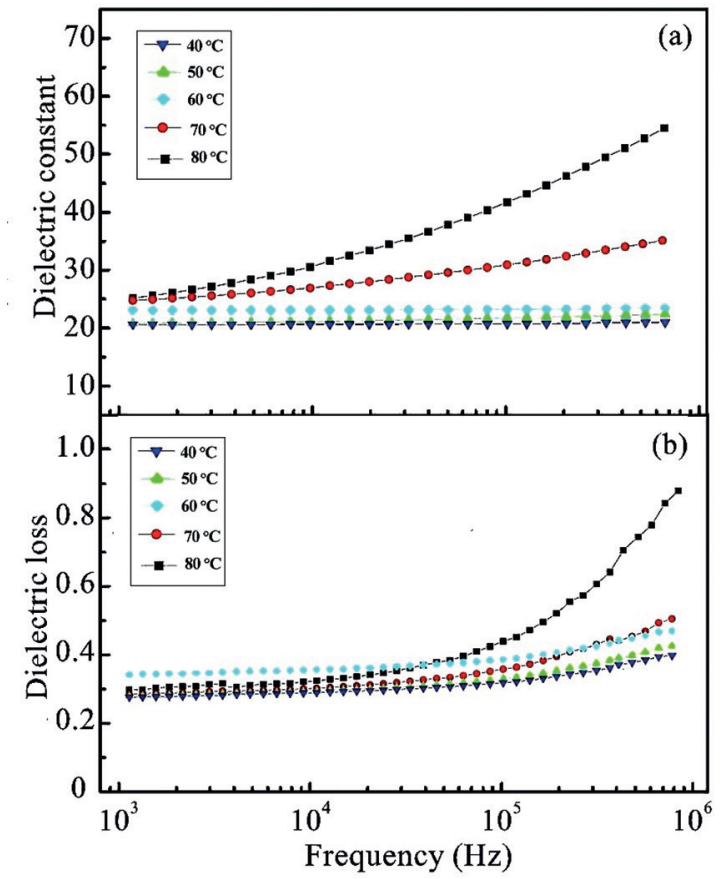

Figure 8: (a \& b) Dependence of dielectric constant/dielectric loss on various frequencies and temperatures

becomes smaller than the frequency of the applied field at low temperatures. The periodic reversal of the applied field occurs so rapidly that excess charge carriers jumping in the field direction is nil. The polarization due to charge piling up at higher free energy barrier sites disappears, which causes a decrease in the values of the dielectric constant and the dielectric loss ${ }^{20-22}$. At low frequencies all the mechanism of polarizations are active and with increasing frequency the contribution from different polarizations start decreasing. As the frequency increases the dipoles do not comply with the varying external field therefore decreasing the value of dielectric constant at low frequency region. From Figure 8 (b), it is observed that the dielectric loss decreases with increase in frequency at different temperatures. The low value of dielectric loss suggests that the glasses are of moderately good quality. Thus the low value of dielectric loss at higher frequencies is important for extending the applications towards photonic, electro-optic devices.

The frequency dependence of the ac conductivity for various temperatures is shown in Figure 9. It is observed that the conductivity increases with increasing frequency. At a given temperature the conductivity is directionally proportional to frequency confirming polaran hopping. From the figure we can observe that conductivity increases as the temperature increases ${ }^{23}$. This increase in conductivity is attributed to the reduction in the space charge polarization at higher frequencies. The poly-dispersive behaviour exhibited is proved by the frequency dependence of the

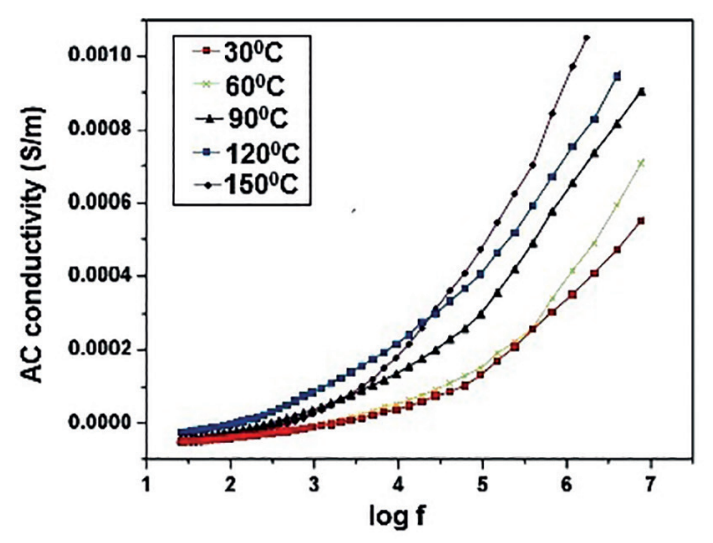

Figure 9: Variation of conductivity with frequency for glass.

ac conductivity. Further as the frequency decreases more and more charge accumulation occurs at the interface between electrode and electrolyte, and hence there is a drop in conductivity at low frequencies.

\section{Conclusion}

$\mathrm{Pr}_{2} \mathrm{O}_{5}$ doped borate glasses were prepared by the conventional melt quenching method. The XRD spectrum revealed that the $\mathrm{Pr}_{2} \mathrm{O}_{5}$ doped borate glasses were amorphous in nature. Photoluminescence properties of $\mathrm{Pr}_{2} \mathrm{O}_{5}$ doped borate glass were analyzed which proves that the prepared glass can be used as a blue up converter in Fibre Optic communication field. FTIR and FT Raman studies were carried out of $\operatorname{Pr}_{2} \mathrm{O}_{5}$ doped borate glass. The disorder in the glass matrix results in the broadening of the obtained peaks. Thermal analyses of the glasses have been done to see the structure of the glasses. The variations of the dielectric constant, the dielectric loss and $\mathrm{AC}$ conductivity with frequency and temperature for $\mathrm{Pr}_{2}$ Odoped borate glass were analyzed. The dielectric studies revealed that both the dielectric constant and the dielectric loss decreased with an increase in the frequency at different temperatures. The low value of dielectric loss suggests that the glasses are of moderately good quality. Also the low value of dielectric loss at higher frequencies is important for extending their applications towards photonic, electro-optic devices.

\section{Acknowledgements}

The authors are very grateful to Anna University, Chennai and SREC Coimbatore for providing characterization techniques for various studies. The author Dr. M. Priya would like to thank the Board of Research in Nuclear Sciences (BRNS) for funding this major research project. 


\section{References}

1. Weber MJ. Handbook of Laser Science and Technology. Boca Raton: CRC Press; 1982.

2. Tandon SP, Sharma YK, Bishnoi NB, Tandon K. Optical Studies on Rare Earth Lasting Materials. Defence Science Journal. 1997;47(2):225-238.

3. Reisfeld R, Jørgensen CK. Excited state phenomena in vitreous materials. In: Gschneidner KA Jr, Bünzli JCG, Pecharski VK, eds. Handbook on the Physics and Chemistry of Rare Earths. Cap 9. Amsterdam: North Holland; 1987.

4. Deike GH. Crosswhite HM, Crosswhite H. Spectraand energy levels of rare earth ions in crystals. New York: Interscience Publishers; 1968.

5. Gao W, Tong Y, Yang Y, Chen G. Monochromic orange emission of $\mathrm{Pr}^{3+}$ ions in phosphate glass. Chinese Optics Letters. 2015;13(10):101602.

6. Zhang F, Bi Z, Huang A, Xiao Z. Luminescence and Judd-Ofelt analysis of the $\operatorname{Pr}^{3+}$ doped fluorotellurite glass. Journal of Luminescence. 2015;160:85-89.

7. Martins VM, Azevedo GA, Andrade AA, Messias DN, do Monte AFG Dantas NO, et al. Spatial and temporal observation of energy transfer processes in Pr-doped phosphate. Optical Materials. 2014;37:387-390.

8. Plaza JL, Aragó C. Characterisation of pure and $\operatorname{Pr}$ doped $\mathrm{BiB}_{3} \mathrm{O}_{6}$ glasses prepared under different thermal conditions. Journal of Alloys and Compounds. 2015;623:178-185.

9. Park JM, Kim HJ, Limsuwan P, Kaewkhao J. Luminescence property of rare-earth-doped bismuth-borate glasses with different concentrations of bismuth and rare-earth material. Journal of the Korean Physical Society. 2012;61(2):248-253.

10. Pisarski WA, Pisarska J, Lisiecki R, Grobelny 1, DominiakDzik G, Ryba-Romanowski W. Luminescence spectroscopy of rare earth-doped oxychloride lead borate glasses. Journal of Luminescence. 2011;131(4):649-652.

11. El-Okr M, Farouk M, El-Sherbiny M, El-Fayoumi MAK, Brik MG. Spectroscopic studies of the $\mathrm{Pr}^{3+}$-doped borovanadate glass. Journal of Alloys and Compounds. 2010;490(1-2):184-189.
12. Padlyak B. Grinberg M, Kuklinski B, Oseledchik Y, Smyrnov O, Kudryavtcev D, et al. Synthesis and optical spectroscopy of the $\mathrm{Eu}$ - and $\mathrm{Pr}$-doped glasses with $\mathrm{SrO}-2 \mathrm{~B}_{2} \mathrm{O}_{3}$ composition. Optica Applicata. 2010;40(2):413-426.

13. Desa JAE, Vaz WA, De Souza BL, Singh M. Optical properties of $\mathrm{Pr}$ and $\mathrm{Nd}$ ions in a borate glass. Glass Technology: European Journal of Glass Science and Technology Part A. 2009;50(4):230-232.

14. El-Okr M, Ibrahem M, Farouk M. Structure and properties of rare-earth-doped glassy systems. Journal of Physics and Chemistry of Solids. 2008;69(10):2564-2567.

15. Cao JC, Lü JT, Guo G. Electron-LO-phonon interaction in wurtzite GaN quantum wells under a magnetic field. Physica B: Condensed Matter. 2008;403(17):2567-2571.

16. Edelman IS, Malakhovskii AV, Potseluyko AM, Zarubina TV, Zamkov AV. Temperature dependencies of intensities of $\mathrm{f}-\mathrm{f}$ transitions in $\mathrm{Pr}^{3+}$ and $\mathrm{Dy}^{3+}$ in glasses. Journal of Non-Crystalline Solids. 2002;306(2):120-128.

17. Sharma YK, Tandon SP, Surana SSL. Laser action in praseodymium doped zinc chloride borophosphate glasses. Materials Science and Engineering: B. 2001;77(2):167-171.

18. Belsky AN, Krupa JC. Luminescence excitation mechanisms of rare earth doped phosphors in the VUV range. Displays. 1999;19(4):185-196.

19. PrajnaShree M, Wagh A, Raviprakash Y, Sangeetha B, Kamath SD. Characterization of pr6o11 doped zinc fluoroborate glass. European Scientific Journal. 2013;9(18):83-92.

20. Sindhu S, Sanghi S, Agarwal A, Seth VP, Kishore N. Effect of $\mathrm{Bi}_{2} \mathrm{O}_{3}$ content on the optical band gap, density and electrical conductivity of $\mathrm{MO} \cdot \mathrm{Bi}_{2} \mathrm{O}_{3} \cdot \mathrm{B}_{2} \mathrm{O}_{3}(\mathrm{M}=\mathrm{Ba}, \mathrm{Sr})$ glasses. Materials Chemistry and Physics. 2005;90(1):83-89.

21. Szu SP, Lin CY. AC impedance studies of copper doped silica glass. Materials Chemistry and Physics. 2003;82(2):295-300.

22. Murugasen P, Shajan D, Sagadevan S. A study of structural, optical and dielectric properties of $\mathrm{Eu}_{2} \mathrm{O}_{3}$ doped borate glass. International Journal of Physical Sciences. 2015;10(20):554-561.

23. Shajan D, Murugasen P, Sagadevan S. Analysis on the structural, spectroscopic, and dielectric properties of borate glas. Digest Journal of Nanomaterials and Biostructures. 2016;11(1):177-183. 